\title{
Endogenous Opioids and the Treatment of Multiple Sclerosis
}

\section{Ian S. Zagon and Patricia J. McLaughlin*}

Department of Neural \& Behavioral Sciences, Pennsylvania State University College of Medicine, Hershey, Pennsylvania, USA

*Corresponding author: Patricia J. McLaughlin, Department of Neural \& Behavioral Sciences, Penn State University College of Medicine, 500 University Drive, MCH109, Hershey, PA 17033-0850, USA, Tel: 717-531-6414; Fax: 717-531-5003; E-mail: pxm9@psu.edu

Received Date: Mar 12, 2014 Accepted Date: Apr 23, 2014 Published Date: Apr 28, 2014

Copyright: (C) 2014 Zagon IS, et al. This is an open-access article distributed under the terms of the Creative Commons Attribution License, which permits unrestricted use, distribution, and reproduction in any medium, provided the original author and source are credited.

\begin{abstract}
Multiple sclerosis is an autoimmune disorder of the central nervous system that affects approximately 400,000 people in the United States and 2 million individuals worldwide. The disease is chronic, often progressive, and manifests through proliferation and activation of T-lymphocytes and astrocytes, resulting in demyelination and axonal damage. Approved therapies are interferon-based or involve T-cell immune modulators; however, many treatments have unacceptable side-effects, are cost-prohibitive, and/or require clinical visits for administration. There is an unmet need for disease-modifying therapies that are non-toxic and readily available. The regulatory pathway involving opioid growth factor (OGF) and its nuclear-associated receptor, OGFr, is involved in several autoimmune diseases including multiple sclerosis. The OGF-OGFr axis appears to be aberrant in that patients with autoimmune disorders often have reduced levels of peptide, an inhibitory growth factor targeting cell proliferation.OGF is an endogenous neuropeptide, chemically termed [Met5]-enkephalin, that ameliorates the course of experimental autoimmune encephalomyelitis when treatment is initiated at the time of induction in mouse models of progressive disease. OGF therapy initiated at the time of disease presentation reversed progressive disease within one week. OGF treatment of the mouse model of relapse-remitting experimental autoimmune encephalomyelitis resulted in a significant reduction in the severity and number of relapses. Treatment with OGF of established relapse-remitting disease diminished peak clinical disease and suppressed relapses. Preclinical studies, as well as clinical observations, support the use of endogenous opioids as safe and effective disease-modifying biotherapeutics.
\end{abstract}

Keywords: Opioid growth factor; Low dose naltrexone; Behavior; Spinal cord; Experimental autoimmune encephalomyelitis; Multiple sclerosis

\section{Abbreviations}

CNS: Central Nervous System; MS: Multiple Sclerosis; EAE: Experimental Autoimmune Encephalomyelitis; PLP: Proteolipid Protein; MOG: Myelin Oligodendrocytic Glycoprotein; IFN- $\gamma$ : Interferon-gamma; IL- $\beta$ : Interleukin beta; TNF- $\alpha$ : Tumor Necrosis Factor alpha; OGF: Opioid Growth Factor; OGFr: Opioid Growth Factor Receptor; NEP: Neprilysin; LDN: Low Dose Naltrexone; NTX: Naltrexone

\section{Introduction}

\section{Multiple sclerosis}

Multiple sclerosis (MS) is a chronic and debilitating autoimmune disease of the central nervous system (CNS) that affects approximately 400,000 individuals in the United States and 2 million individuals worldwide [1]. MS occurs in two forms - progressive (primary or secondary) and relapse-remitting, and many patients with relapseremitting forms often develop a more progressive, non-remitting disorder later in life. Although the etiology of MS is unknown, women and individuals of countries in northern latitudes have a greater incidence of MS; deficiencies in vitamin D absorption and some genetic instability are traits associated with the disorder [1,2]. MS is a triphasic disease involving astrocyte activation that leads to inflammation and recruitment of activated $\mathrm{T}$ cells to the CNS, and subsequent demyelination, axonal damage, and neurodegeneration [1-3].

\section{Current Therapies}

The FDA has approved seven treatments that target myelin repair and neuroprotection including $\beta$-interferon products marketed as Betaferon, Avonex or Rebif, glatiramer acetate (Copaxone), natalizumba (Tysabri), fingolimod (Gilenya) and mitozantrone (Novantrone). Many of these therapies carry warnings of serious and possibly life-threatening side effects [3-11]. Two of the most widely used therapies are the oral compound fingolimod and Copaxone. Gilenya $^{\text {tix }}$ (fingolimod) is a sphyingosine 1-phophate receptor modulator that prevents migration of lymphocytes from the periphery to CNS, and has shown promise for reducing the number of relapses. Copaxone (glatimer acetate) is a synthetic peptide that imitates myelin proteins, but the mechanism of action is unknown. Because MS has an onset during the reproductive period in a women's life, concerns over treatment and pregnancy have been addressed [6]. Many of the treatments have not been studied in laboratory settings with pregnant animals. Moreover, current treatment regimens are expensive ( $\$ 30,000 /$ year), and compliance is often marginal. Thus there is a need for disease-modifying therapies that are non-toxic and inexpensive.

\section{Animal Models of Disease}

The widely used animal model for MS is experimental autoimmune encephalomyelitis (EAE) $[12,13]$. Chronic progressive EAE is induced by immunization with myelin oligodendrocytic glycoprotein (MOG35-55), whereas a relapse-remitting form of EAE can be induced by immunization with proteolipid protein (PLP139-151) 
$[12,14,15]$. Although the animal models do not correspond to the etiology of MS, the pro-inflammatory diseases are similar, as the levels of IFN- $\gamma$, IL- $1 \beta$, and TNF- $\alpha$ are upregulated in EAE and MS and both disorders are characterized by CNS demyelination and neurodegeneration. Using the MOG-induced EAE model, the course of the disease has been categorized into discrete phases [16]. Immediately following peripheral immunization, reactive $\mathrm{T}$ cells proliferate in lymph nodes and spleen, and initiate cytokine production and secretion [16]. The autoreactive T cells migrate to the CNS, recognize antigen-presenting cells, become activated and begin the inflammation cascade leading to tissue injury. Other lymphocytes remain in "draining" inguinal or cervical nodes that are identified by their enlargement and hyperproliferation of T and B cells. In the CNS, the antigen presenting cells continue pro-inflammatory stimulation and lead to axonal damage and neurodegeneration. This cascade of events is commensurate with the pathophysiology of MS [17], with the understanding that the initial immunization in MS is unknown and autoimmune in nature. Each of these phases of EAE can be modulated by endogenous opioids through the opioid growth factor (OGF) OGF receptor (OGFr) axis.

\section{Role of Endogenous Opioids in the Etiology of Disease}

Endorphins and enkephalins comprise a class of neuropeptides termed endogenous opioids. These peptides have a role in a variety of diseases including autoimmune disorders [18-21]. $\beta$-endorphin has been measured in the serum and cerebrospinal fluid of MS patients [19-21], with peptide levels fluctuating during inactive MS. MS patients often undergo remission in pregnancy, a time when endogenous opioids are known to be elevated, and patient-provided evidence as well as physician's reports indicate that endogenous opioids such as [Met5]-enkephalin (i.e., OGF) levels are altered [20].

Enkephalins and enkephalin proteases also may have an important role in the etiology of MS [22-29]. The neprilysin (NEP) family of zinc metallopeptidases, including neprilysin and endothelin-converting enzyme-2 (ECE-2), are expressed at the cell surface [26]. Enzymatically, neprilysin functions both as an endopeptidase and as a dipeptidylcarboxypeptidase to inactivate neuropeptides. Neprilysin degrades enkephalins in the mammalian brain and inactivates circulating neuropeptides [27]. Neprilysin, also termed as CD10 or common acute lymphoblastic leukemia antigen, is expressed on the surface of lymphocytes in some disease states. These and other observations have resulted in considerable clinical interest in neprilysin/CD10 as a potential target in neurodegeneration. Neprilysin is a major degrading enzyme of amyloid-beta peptide (A-beta) in the brain; down-regulation of neprilysin activity may contribute to the development of Alzheimer's disease by promoting A-beta accumulation. Other studies have shown that cellular progenitors of CD10 can differentiate $\mathrm{T}$ or B lymphocytes or natural killer cells. Expression of CD10 is an indicator of certain lymphomas and leukemias such as $\mathrm{T}$ cell lymphoma and Burkitt's lymphoma. Neprilysin actively degrades a number of signaling neuropeptides including enkephalins, substance $\mathrm{P}$, and atrial natriuretic factor [26-29], thus implicating a role of aberrant levels of endogenous opioids and/or their enkephalinases in disease.

Two opioid peptide proteases, CD10 and CD13, that break down OGF are increased in patients with active MS, and reduced in patients undergoing remission [24,25]. An increase in CD10 (neutral endopeptidase-NEP; EC 3.4.24.11) and CD13 (aminopeptidase N; AP$\mathrm{N}$, EC 3.4.11.2) occurs in MS patients during the course of exacerbation and chronic MS, but expression of these peptidases are low during phases of remission [24,25]. Because these ectoenzymes are enkephalin-degrading, enkephalins which inhibit cell proliferation have reduced expression and the end result is uncontrolled $\mathrm{T}$ cell proliferation and exacerbation of MS. Data on decreased enkephalins and elevated enkephalinases in MS patients suggests an important connection between endogenous opioids and MS.

\section{Role of Endogenous Opioids in the Amelioration of Disease: Basic Science}

Endogenous opioids such as OGFor endogenous secretion of OGF by upregulation of the OGF-OGFr axis following systemic low dosages of naltrexone (LDN) reverse the progression of experimental autoimmune encephalomyelitis (EAE), prevent neuronal damage in the CNS, and reduce the frequency and severity of relapses in a relapse-remitting model of EAE [30-39]. Mouse models of chronic progressive EAE induced by MOG35-55 injections, as well as relapseremitting EAE, induced by PLP139-151 have been successfully to demonstrate the safety and efficacy of OGF or LDN treatment for MS [34-39].

\section{The OGF-OGFr Axis: General Concepts}

OGF, chemically termed [Met5]-enkephalin, is a constitutively expressed native opioid that interacts with OGFr to decrease cell replication and growth during neoplasia, development, wound healing, and angiogenesis [30,31]. OGF activity is not cell, tissue or organ specific, and its action is stereospecific and reversible. OGF is non-cytotoxic/non-apoptotic inducing, not associated with differentiation, migration, adhesion, or invasion, and occurs at physiologically relevant concentrations. The mechanisms of OGF action are known [40,41]. OGF enters cells through clathrin-mediated endocytosis, interacts with the OGF receptor (OGFr), and targets the cyclin-dependent inhibitory kinases p16 and p21 to delay cells in the G1/S phase of the cell cycle [11,12]. OGF influences tissue organization. Addition of exogenous OGF [39] or introduction of OGFr by recombinant technology or delivery by a gene gun in vivo or transfection in vitro exacerbates the OGF-OGFr equilibrium and enhances the inhibitory action $[42,43]$. Disruption of peptide-receptor interaction by sustained opioid receptor blockade (e.g., the potent and long-acting opioid antagonist naltrexone), OGF-specific antibodies, or antisense/siRNA constructs for OGFr results in a substantial increase in cell number compared to control levels, indicating the tonic and constitutive nature of OGF-OGFr interfacing.

OGF and LDN Treatment Initiated at the Time of MOG-Induction in Progressive EAE Secretion of the endogenous opioid OGF can be induced by intermittent blockade of the OGF-OGFr axis using low dosages of naltrexone (LDN). The short duration of blockade upregulates peptide and receptor facilitating interaction when the antagonist naltrexone is no longer available [30]. Treatment of mice with either $10 \mathrm{mg} / \mathrm{kg}$ OGF or $0.1 \mathrm{mg} / \mathrm{kg}$ naltrexone (LDN) beginning at the time of disease induction modifies the onset and progression of disease. Studies conducted over a 60-day period of time with daily treatment initiated at the time of immunization demonstrated that in comparison to MOG-immunized mice receiving saline, OGF prevents the expression of disease in $37 \%$ of mice and reduces the severity and disease indices of EAE (Figure 1). In several experiments, OGF increased remission by 6 -fold relative to control mice, and reduced activated astrocyte proliferation, demyelination, and neuronal damage. 
Page 3 of 6

OGF or LDN treatment of mice with EAE resulted in no deleterious long-term repercussions and did not exacerbate EAE across a considerable span of time. Studies revealed that OGF or LDN halt progression of disease, reverse neurological deficits, and prevent the onset of neurological disorders in comparison to EAE mice receiving saline [34-36].

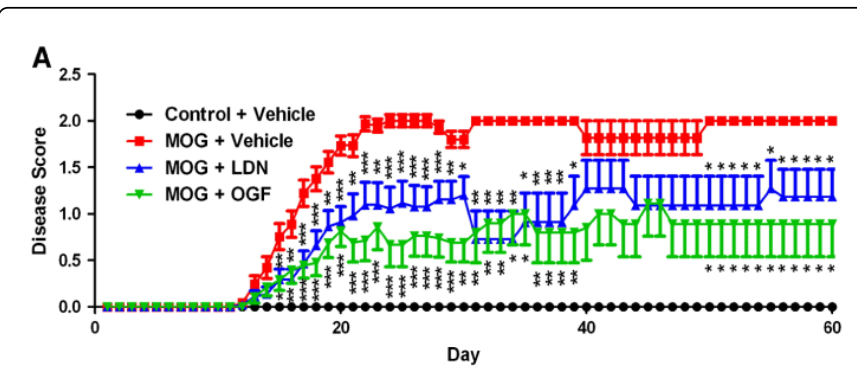

Figure 1. Behavioral scores of mice with chronic progressive EAE induced by MOG injections and treated daily from the time of initiation of disease (day 0 ) with either saline (vehicle), $10 \mathrm{mg} / \mathrm{kg}$ OGF, or $0.1 \mathrm{mg}$ naltrexone (LDN). Mean behavioral scores are significantly different from MOG+Vehicle mice at $\left.\mathrm{p}<0.05{ }^{*}\right)$, $\left.\mathrm{p}<0.01{ }^{* *}\right)$, and $\left.\mathrm{p}<0.001{ }^{(* *}\right)$. (Adapted from Rahn et al., [35])

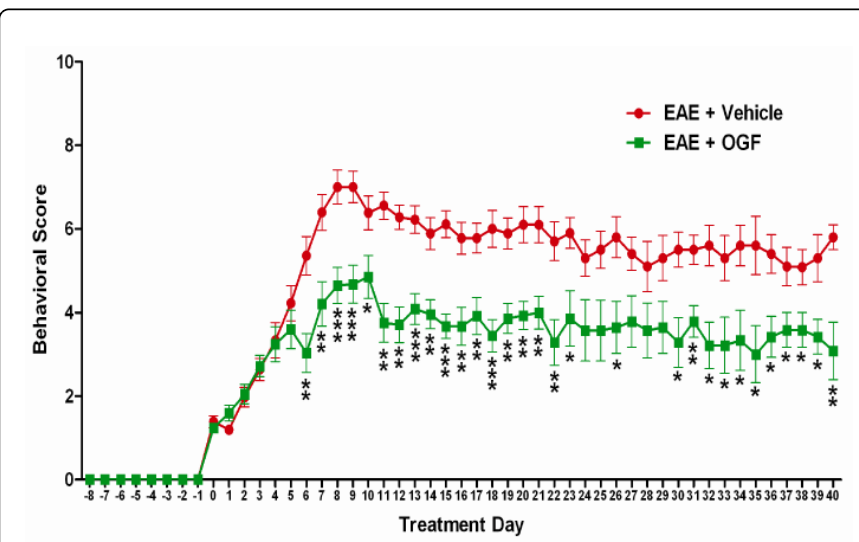

Figure 2. Disease scores of MOG-induced animals with established EAE disease and treated with vehicle (saline) or $10 \mathrm{mg} / \mathrm{kg}$ OGF for 40 days post disease onset. Mice were observed daily by two individuals, with one masked to the treatment group; behavioral scale ranged from 0-10 (death). Significantly different from EAE +vehicle mice at $\left.\mathrm{p}<0.05\left(^{*}\right), \mathrm{p}<0.01{ }^{* *}\right)$, and $\left.\mathrm{p}<0.001{ }^{* * *}\right)$. (Adapted from Campbell et al., [37])

\section{OGF Treatment Initiated with Established Chronic Progressive Disease}

Investigations on the effectiveness of OGF for treatment of mice with established progressive EAE (clinical signs for 2 consecutive days) were conducted with mice being evaluated over a 40 day period of time [37]. All MOG-immunized mice displayed clinical signs of disease within 9-10 days, and were randomized to receive daily injections of either OGF $(10 \mathrm{mg} / \mathrm{kg})$ or saline. Within 6 days of OGF treatment, behavioral scores were markedly reduced relative to controls (EAE+vehicle mice)(Figure 2) [37], suggesting a reversal of the course of disease. Whereas mice with EAE receiving OGF had behavioral scores of 2 to 3 (foot faults and wobbly gait) based on an expanded 10-point scoring system, control animals had behavioral scores averaging 6.5 to 7 (hindlimb and forelimb paralysis). Neuropathological evaluation of the lumbar regions of the CNS revealed reduced levels of inflammation (activated astrocytes and microglia) and diminished demyelination [37]. Immunohistochemical staining of lumbar spinal cord showed elevated numbers of microglia/ macrophage and astrocytes in saline-injected mice with disease relative to normal mice. Conversely, mice with established disease but treated with OGF had significant reductions in microglia within 5 days of treatment that were sustained for all 40 days of evaluation. Astrocyte number in the control group was elevated 5-fold by 10 days of disease, and significantly reduced in mice treated with OGF [38]. Thus, treatment with endogenous opioids initiated at the time of established chronic progressive EAE, a clinically relevant paradigm, reverses the progression of clinical disease [37].

\section{OGF Inhibition of Relapse-Remitting EAE with Treatment Initiated at the Time of Disease Induction}

Eighty-five percent of patients with MS have the relapsing form $[1,2]$. The mouse model for the relapse-remitting form of EAE is established by immunization of SJL/J mice with PLP139-151 (i.e., relapse-remitting EAE; RR-EAE). When endogenous opioids were administered concomitantly with the induction of disease, mice receiving OGF has substantial reduction in clinical signs of disease, as well as decreased neuropathology in the CNS [39]. Cumulative disease scores (summation of behavioral scores for all mice) for PLP immunized mice receiving saline were $145 \pm 23$ in comparison to a disease index of $78 \pm 16$ for mice receiving OGF, a $46 \%$ decrease. Mice were monitored daily for periods of remission and relapse. A complete remission was considered when the animal returned to a score of 0.5 or less for two consecutive days; a relapse was the period of time when behavioral scores for an individual mouse were 2 or more points higher than their average running behavioral score for 2 consecutive days [39]. In comparison to RR-EAE mice receiving saline, OGF effectively reduced the severity of the peak disease and prevented all subsequent relapses (Figure 3) [39]. PLP immunized mice receiving saline had 4.5-fold more relapses than mice receiving OGF. Histological analyses of spinal cord tissue from mice in both treatment groups reveal reduced neuropathology following exposure to OGF. On day 14 (peak disease), mice immunized with PLP and receiving OGF had $50 \%$ fewer activated astrocytes relative to mice receiving saline. At the termination of the study on day 55, immunized mice receiving saline had 2-fold more astrocytes detected in the CNS than animals receiving OGF. Neuropathology of the lumbar spinal cord corroborated findings of reduced microglia and $\mathrm{T}$ lymphocytes in OGF-treated mice with RR-EAE relative to controls. In summary, endogenous opioid treatment of RR-EAE animals reduced the median cumulative disease scores by $66 \%$, prolonged periods of remission, and diminished the frequency and severity of disease relapses.

\section{OGF and LDN Treatment of Established Disease Inhibited the Progression of Relapse-Remitting EAE}

A final paradigm of investigation involved initiating treatment with endogenous opioids after clinical signs of RR-EAE appeared for 2 consecutive days; this model closely reflects the majority of MS patients who present in a clinic after several days of tremors, stumbling, or dizziness. Immunization of mice with PLP139-151 resulted in the first appearance of clinical signs of RR-EAE on day 9, 
with peak disease occurring within 2-3 days. Saline-treated mice with RR-EAE had mean peak scores of 4.8, corresponding to limb paralysis, gait abnormalities, and altered tail tonicity. In comparison, the mean behavioral scores for RR-EAE mice receiving OGF were significantly lower than controls at the time of peak disease, and remained reduced on 27 of the 32 days following peak disease(Figure 4). OGF treatment of mice with RR-EAE resulted in a majority of mice having one or more remissions in comparison to only one of 18 mice receiving saline showing behavioral remission. Not only was the frequency of remission increased by OGF, but the duration of remission following OGF was markedly prolonged relative to mice receiving saline. In summary, endogenous opioid treatment of the mouse model of relapse-remitting disease was effective when initiated early in the course of disease as well as at the time of observable clinical signs of disease, comparable to clinically isolated syndrome.

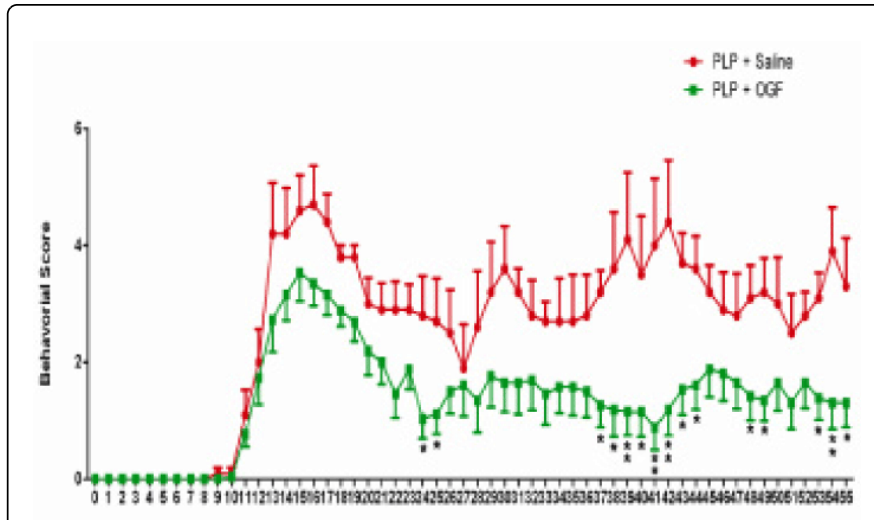

Figure 3. Behavioral profile of RR-EAE in mice immunized with PLP139-151 and treated daily with either $10 \mathrm{mg} / \mathrm{kg}$ OGF (PLP +OGF) or saline (PLP+saline) beginning at the time of immunization. Behavior was scored daily. Significantly different behavioral scores at $\left.\mathrm{p}<0.05\left(^{*}\right), \mathrm{p}<0.01{ }^{* *}\right)$. (Adapted from Hammer et al., [39])

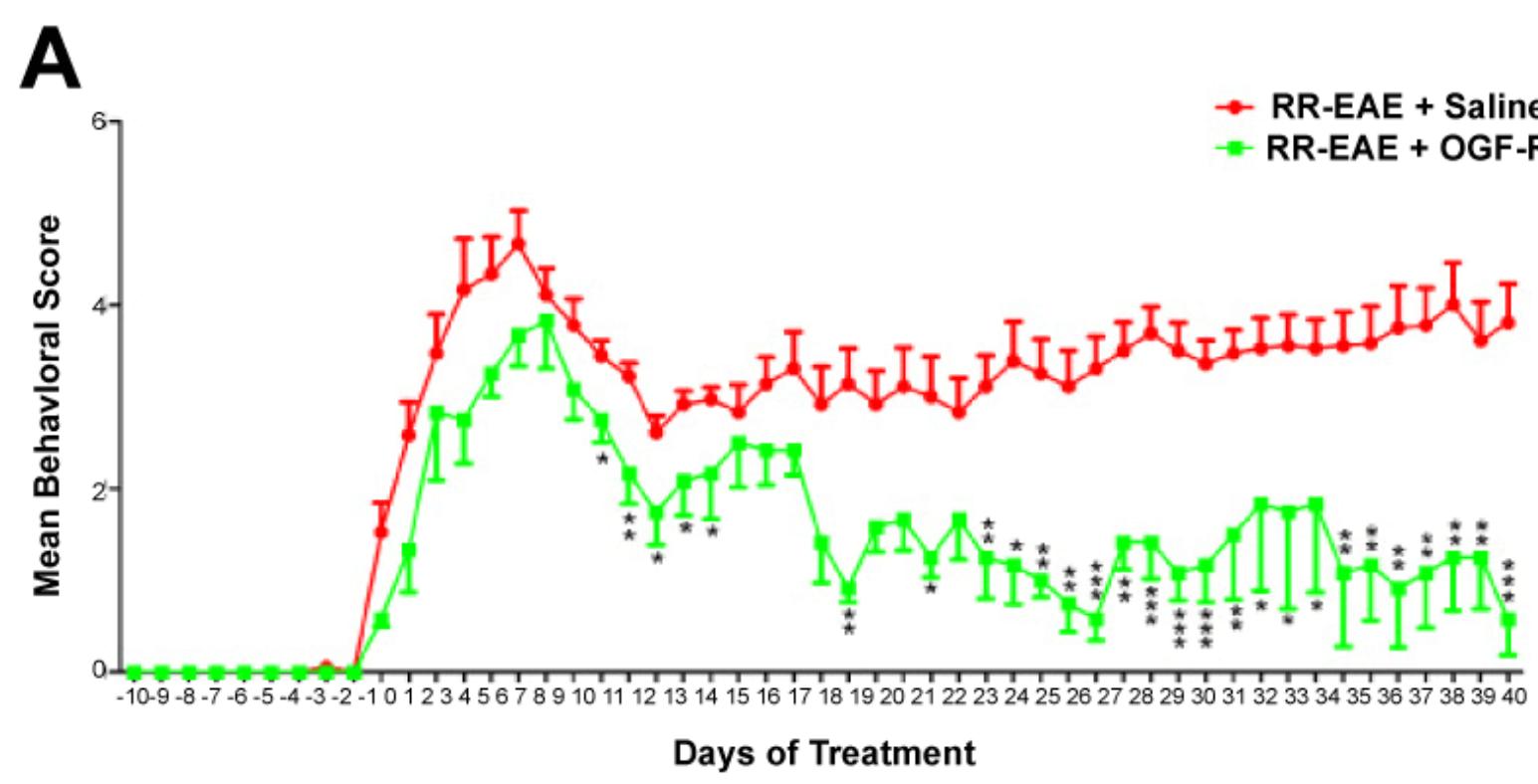

Figure 4. Behavioral profile of established RR-EAE in mice treated daily with $10 \mathrm{mg} / \mathrm{kg}$ OGF (RR+EAE + OGR-R; $\mathrm{n}=8)$ or saline $(\mathrm{RR}-\mathrm{EAE}+$ Saline; $n=9$ ) beginning after 2 days of observed behavior effects. Behavior was scored daily by 2 observers, one masked to treatment. Significantly different behavioral scores at $\mathrm{p}<0.05\left(^{*}\right), \mathrm{p}<0.01\left(^{* *}\right) ; \mathrm{p}<0.001\left(^{* * *}\right)$.

\section{Role of Endogenous Opioids in Treatment of Multiple Sclerosis: Clinical Trials}

Confirmation of the efficacy of the biotherapy OGF, and understanding the underlying mechanistic pathways in MS, is particularly attractive since OGF is safe, non-toxic, and efficacious as shown in Phase I [44] and Phase II [45] studies for other indications. Furthermore, LDN is non-toxic and effective in clinical trials for treatment of other autoimmune disorders including Crohn's disease [46] and fibromyalgia [47]. Thus, knowledge that OGF plays a regulatory role in the etiology and pathogenesis of EAE(and MS) encourages biological investigations on the OGF-OGFr axis as a therapeutic target. At this time, OGF is not available by prescription, whereas LDN can be obtained as an off-label, prescription therapeutic under physician's guidance. At least three clinical trials have been published whereby the opioid antagonist for the OGF-OGFr pathway, LDN, was demonstrated to increase the quality of life of MS patients with relapse-remitting MS or secondary progressive MS, and significantly improve mental health [48-50]. In a single center, doublemasked, placebo-controlled, crossover study, patients were given 4.5 mg naltrexone nightly. LDN was found to be well-tolerated and no serious adverse events occurred [49]. A research team led by Dr. Maira 
Gironi in Milan reported that 6 months of LDN treatment in a phase II multicenter trial demonstrated that LDN was safe and well tolerated [50]. Thus, the reports on controlled clinical trials, as well as numerous websites (http://www.ldnnow.co.uk/,

http:// www.ldnresearchtrust.org/) show that LDN is a safe, non-toxic and effective therapy. An outcome of all clinical trials is the recommendation for additional study using OGF or LDN with longer duration of therapy.

\section{Conclusions}

Because modulation of OGF and OGFr in EAE (and MS) can change the course of disease, one can hypothesize that both the peptide and receptor play an important role in EAE/MS, and that either peptide or receptor, or both, may be defective during the disease process. Given that exogenous administration of OGF reduces clinical behavior in animal models of progressive [34-37] and relapseremitting [39], disease, and that $\mathrm{LDN}$ is effective in clinical trials of patients with MS [46-48], it can be postulated that the receptor is intact and functioning. Circulating levels of OGF, as well as degradation of the peptide, are of interest as possibly becoming aberrant during the course of disease. Laboratory studies have shown that OGF plays an important role in EAE/MS by inhibiting the proliferation of cells related to the inflammatory process thus demonstrating that the endogenous opioids target disease-modifying pathways [38]. In vitro experiments have shown that OGF inhibits cell proliferation in a receptor-mediated manner of astrocytes isolated from cerebral cortices [38]. Behavioral studies have shown that OGF, and LDN, are effective at reducing clinical signs of EAE, reversing the progression of EAE, and preventing subsequent relapses in RR-EAE. In conjunction with clinical data on LDN, the OGF-OGFr regulatory axis is a new paradigm of disease-modifying therapy for multiple sclerosis.

\section{Acknowledgments}

This work was supported by in part by a generous gift from The Paul K. and Anna E. Shockey Family Foundation, and private donations to the Penn State LDN fund. The authors have no competing interests.

\section{References}

1. Banci L, Bertini I, Boca M, Girotto S, Martinelli M, et al. (2008) SOD1 and amyotrophic lateral sclerosis: mutations and oligomerization. PLoS One 3: e1677.

2. http://www.uptodate.com/contents/epidemiology-and-clinical-featuresof-multiple-sclerosis-in-adults?

detectedLanguage $=$ en \&source $=$ search_result\&search $=$ multiple +sclerosis\&selectedTitle $=2 \sim 150$ \&provider $=$ noProvider

3. Fox EJ, Rhoades RW (2012) New treatments and treatment goals for patients with relapsing-remitting multiple sclerosis. Curr Opin Neurol 25 Suppl: S11-19.

4. Stoll SS, Nieves C, Tabby DS, Schwartzman R (2012) Use of therapies other than disease-modifying agents, including complementary and alternative medicine, by patients with multiple sclerosis: a survey study. J. Am Osteopath Assoc 112: 22-28.

5. Hadjigeorgiou GM, Doxani C, Miligkos M, Ziakas P, Bakalos G, et al. (2013) A network meta-analysis of randomized controlled trials for comparing the effectiveness and safety profile of treatments with marketing authorization for relapsing multiple sclerosis. J Clin Pharm Ther 38: 433-439.
6. Cree BA (2013) Update on reproductive safety of current and emerging disease-modifying therapies for multiple sclerosis. Mult Scler 19: 835-843.

7. Rudick RA, Kappos L, Kinkel R, Clanet M, Phillips JT, et al. (2011) Gender effects on intramuscular interferon beta-1a in relapsing-remitting multiple sclerosis: analysis of 1406 patients. Mult Scler 17: 353-360.

8. Herndon RM (1998) Treatment of multiple sclerosis with the interferonbetas: comparative risks and benefits. BioDrugs 10: 463-470.

9. Devonshire V, Havrdova E, Radue EW, O'Connor P, Zhang-Auberson L (2012) Relapse and disability outcomes in patients with multiple sclerosis treated with fingolimod: subgroup analyses of the double-blind, randomised, placebo-controlled FREEDOMS study. Lancet Neurol 11: 386-388.

10. Chiba K, Kataoka H, Seki N, Shimano K, Koyama M, et al. (2011) Fingolimod (FTY720), sphingosine-1-phosphate receptor modulator, shows superior efficacy as compared with interferon- $\beta \mathrm{n}$ mouse experimental autoimmune encephalomyelitis. Int Immunopharmacol 11: 366-372.

11. Killestein J, Rudick RA, Polman CH (2011) Oral treatment for multiple sclerosis. Lancet Neurol 10: 1026-1034.

12. Constantinescu CS, Farooqi N, O'Brien K, Gran B (2011) Experimental autoimmune encephalomyelitis (EAE) as a model for multiple sclerosis (MS). Br J Pharmacol 164: 1079-1106.

13. Steinman L, Zamvil SS (2005) Virtues and pitfalls of EAE for the development of therapies for multiple sclerosis. Trends Immunol 26: 565-571.

14. Mangano K, Nicoletti A, Patti F, Donia M, Malaguarnera L, et al. (2010) Variable effects of cyclophosphamide in rodent models of experimental allergic encephalomyelitis. Clin Exp Immunol 159: 159-168.

15. Jackson SJ, Lee JE, Nikodemova M, Fabry Z, Duncan ID (2009). Quantification of myelin and axon pathology during relapsing progressive experimental autoimmune encephalomyelitis in the Biozzi $\mathrm{ABH}$ mouse. Journal of Neuropathology and Experimental Neurology 68: 616-625.

16. Fletcher JM, Lalor SJ, Sweeney CM, Tubridy N, Mills KHG (2010) T cells in multiple sclerosis and experimental autoimmune encephalomyelitis. Clin Exp Immunol 162:1-11.

17. Peterson LK, Fujinami RS (2007) Inflammation, demyelination, neurodegeneration and neuroprotection in the pathogenesis of multiple sclerosis. J Neuroimmunol 184: 37-44.

18. Gironi M, Martinelli V, Brambilla E, Furlan R, Panerai AE, et al. (2000) Beta-endorphin concentrations in peripheral blood mononuclear cells of patients with multiple sclerosis: effects of treatment with interferon beta. Arch Neurol 57: 1178-1181.

19. Jankovic BD (1991) Enkephalins and immune inflammatory reactions. Acta Neurol (Napoli) 13: 433-441.

20. Csontos K, Rust M, Höllt V, Mahr W, Kromer W, et al. (1979) Elevated plasma beta-endorphin levels in pregnant women and their neonates. Life Sci 25: 835-844.

21. Demina TL, Bö̈ko AN, Rossel's AN, Balashov KE, Popova NF (1990) [Study of cellular immunity and the opioid peptide system in patients with multiple sclerosis]. Zh Nevropatol Psikhiatr Im S S Korsakova 90: 19-24.

22. Weir C1, McNeill A, Hook S, Harvie M, La Flamme AC, et al. (2006) Critical role of preproenkephalin in experimental autoimmune encephalomyelitis. J Neuroimmunol 179: 18-25.

23. Linner KM, Quist HE, Sharp BM (1995) Met-enkephalin-containing peptides encoded by proenkephalin A mRNA expressed in activated murine thymocytes inhibit thymocyte proliferation. J Immunol 154: 5049-5060.

24. Ziaber J, Baj Z, Pasnik J, Chmielewski H, Tchorzewski H (2000) Increased expression of neutral endopeptidase (NEP) and aminopeptidase $\mathrm{N}$ (APN) on peripheral blood mononuclear cells in patients with multiple sclerosis. Immunol. Letters 71: 127-129. 
25. Ziaber J, PaÅnik J, Baj Z, Pokoca L, Chmielewski H, et al. (1998) The immunoregulatory abilities of polymorphonuclear neutrophils in the course of multiple sclerosis. Mediators Inflamm 7: 335-338.

26. Sahli S, Stump B, Welti T, Schweizer WB, Diederich R, et al. (2005) A new class of inhibitors for the metalloprotease neprilysin based on a central imidazole scaffold. Helvetica Chim Acta 88: 707-730.

27. Oefner C, Roques BP, Fournie-Zaluski MC, Dale GE (2004) Structural analysis of neprilysin with various specific and potent inhibitors. Acta Crystallogr D Biol Crystallogr 60: 392-396.

28. Hedge LG, Yu C, Madhave C, Araki R, Villarreal J, et al. (2011) Comparative efficacy of AHU-377, a potent nerpilysin inhibitor, in two rat models of volume-dependent hypertension. BMC Pharmacology 11: 33-34.

29. Gu J, Noe A, Chandra P, Al-Fayoumi S, Ligueros-Saylan M, et al. (2010) Pharmacokinetics and pharmacodynamics of LCZ696, a novel dualacting angiotensin receptor-neprilysin inhibitor (ARNi). J Clin Pharmacol 50: 401-414.

30. McLaughlin PJ, Zagon IS (2012) The opioid growth factor-opioid growth factor receptor axis: homeostatic regulator of cell proliferation and its implications for health and disease. Biochem Pharmacol 84: 746-755.

31. Zagon IS, Verderame MF, McLaughlin PJ (2002) The biology of the opioid growth factor receptor (OGFr). Brain Res Brain Res Rev 38: 351-376.

32. Zagon IS, Donahue RN, Bonneau RH, McLaughlin PJ (2011) T lymphocyte proliferation is suppressed by the opioid growth factor ([Met5]-enkephalin)-opioid growth factor receptor axis: Implication for the treatment of autoimmune diseases. Immunobiology 216:579-590, PMID:20965606.

33. Zagon IS, Donahue RN, Bonneau RH, McLaughlin PJ (2011) B lymphocyte proliferation is suppressed by the opioid growth factoropioid growth factor receptor axis: Implication for the treatment of autoimmune diseases. Immunobiology 216: 173-183. PMID:20598772

34. Zagon IS, Rahn KA, Bonneau RH, Turel AP, McLaughlin PJ (2010) Opioid growth factor suppresses expression of experimental autoimmune encephalomyelitis. Brain Res 1310: 154-161.

35. Rahn KA, McLaughlin PJ, Zagon IS (2011) Prevention and diminished expression of experimental autoimmune encephalomyelitis by low dose naltrexone (LDN) or opioid growth factor (OGF) for an extended period: Therapeutic implications for multiple sclerosis. Brain Res 1381: 243-253.

36. Zagon IS, Rahn KA, Turel AP, McLaughlin PJ (2009) Endogenous opioids regulate expression of experimental autoimmune encephalomyelitis: a new paradigm for the treatment of multiple sclerosis. Exp Biol Med (Maywood) 234: 1383-1392.

37. Campbell AM, Zagon IS, McLaughlin PJ (2012) Opioid growth factor arrests the progression of clinical disease and spinal cord pathology in established experimental autoimmune encephalomyelitis. Brain Res 1472: 138-148.
38. Campbell AM, Zagon IS, McLaughlin PJ (2013) Astrocyte proliferation is regulated by the OGF-OGFr axis in vitro and in experimental autoimmune encephalomyelitis. Brain Res Bull 90: 43-51.

39. Hammer LA, Zagon IS, McLaughlin PJ (2013) Treatment of a relapseremitting model of multiple sclerosis with opioid growth factor. Brain Res Bull 98: 122-131.

40. Cheng F, McLaughlin PJ, Verderame MF, Zagon IS (2009) The OGFOGFr axis utilizes the p16INK4a and p21WAF1/CIP1 pathways to restrict normal cell proliferation. Mol Biol Cell 20: 319-327.

41. Cheng F, McLaughlin PJ, Banks WA, Zagon IS (2010) Internalization of the opioid growth factor, [Met5]-enkephalin, is dependent on clathrinmediated endocytosis for downregulation of cell proliferation. Am J Physiol Regul Integr Comp Physiol 299: R774-785.

42. Zagon IS, Sassani JW, Malefyt KJ, McLaughlin PJ (2006) Regulation of corneal repair by particle-mediated gene transfer of opioid growth factor receptor complementary DNA. Arch Ophthalmol 124: 1620-1624.

43. McLaughlin PJ, Verderame MF, Hankins JL, Zagon IS (2007) Overexpression of the opioid growth factor receptor downregulates cell proliferation of human squamous carcinoma cells of the head and neck. Int J Mol Med 19: 421-428.

44. Smith JP, Conter RL, Bingaman SI, Harvey HA, Mauger DT, et al. (2004) Treatment of advanced pancreatic cancer with opioid growth factor: phase I. Anticancer Drugs 15: 203-209.

45. Smith JP, Bingaman SI, Mauger DT, Harvey HH, Demers LM, et al (2010) Opioid growth factor improves clinical benefit and survival in patients with advanced pancreatic cancer. Open Access J Clin Trials 2010: 37-48.

46. Smith JP, Bingaman SI, Ruggiero F, Mauger DT, Mukherjee A, et al. (2011) Therapy with the opioid antagonist naltrexone promotes mucosal healing in active Crohn's disease: a randomized placebo-controlled trial. Dig Dis Sci 56: 2088-2097.

47. Younger J, Noor N, McCue R, Mackey S (2013) Low-dose naltrexone for the treatment of fibromyalgia: findings of a small, randomized, doubleblind, placebo-controlled, counterbalanced, crossover trial assessing daily pain levels. Arthritis Rheum 65: 529-538.

48. Sharafaddinzadeh N, Moghtaderi A, Kashipazha D, Majdinasab N, Shalbafan B (2010) The effect of low-dose naltrexone on quality of life of patients with multiple sclerosis: a randomized placebo-controlled trial. Mult Scler 16: 964-969.

49. Cree BA, Kornyeyeva E, Goodin DS (2010) Pilot trial of low-dose naltrexone and quality of life in multiple sclerosis. Ann Neurol 68: $145-150$

50. Gironi M, Martinelli-Boneschi F, Sacerdote P, Solaro C, Zaffaroni M, et al. (2008) A pilot trial of low-dose naltrexone in primary progressive multiple sclerosis. Mult Scler 14: 1076-1083.
This article was originally published in a special issue, entitled:

"Neurodegenerative Diseases: Symptoms and Therapeutics", Edited by Dr. Jin J Luo, Temple University School of Medicine, USA 